\title{
The Anti-tumor Effect of Cabozantinib on Ovarian Clear Cell Carcinoma In Vitro and In Vivo
}

\author{
MAKIKO NAKATANI ${ }^{1}$, HIDEMICHI WATARI ${ }^{1}$, TAKASHI MITAMURA ${ }^{1}$, LEI WANG $^{2}$, \\ YUTAKA HATANAKA ${ }^{3}$, KANAKO C. HATANAKA ${ }^{3}$, KOHEI HONDA ${ }^{4}$, TOSHIYUKI NOMURA $^{4}$, \\ HIROSHI NISHIHARA ${ }^{2}$, SHINYA TANAKA ${ }^{2}$ and NORIAKI SAKURAGI ${ }^{1}$ \\ Departments of ${ }^{1}$ Obstetrics and Gynecology, and ${ }^{2}$ Cancer Pathology, \\ Hokkaido University Graduate School of Medicine, Sapporo, Japan; \\ ${ }^{3}$ Department of Surgical Pathology, Hokkaido University Hospital, Sapporo, Japan; \\ ${ }^{4}$ Oncology Drug Discovery Unit Pharmaceutical Research Division, \\ Takeda Pharmaceutical Co. Ltd., Fujisawa, Japan
}

\begin{abstract}
Background: Several reports have shown that the overexpression of the MET proto-oncogene, receptor tyrosine kinase (MET), was more frequently observed in clear cell carcinoma (CCC) than in non-CCC. We evaluated the antitumor activity of cabozantinib, that targets MET. Materials and Methods: A gene expression analysis of tumors from human ovarian cancers was carried out by transcriptome sequencing. An in vitro 3-(4, 5-dimethylthiazolyl-2)-2, 5diphenyltetrazolium bromide assay (MTT assay) and in vivo experiments were performed to determine the activity of cabozantinib. Results: The MET levels were higher in tumors with CCC than high-grade serous carcinoma (2.2-fold). Cabozantinib inhibited cell viability and phosphorylation of $A K T$ and MAPK under the treatment of hepatocyte growth factor in RMG-I CCC cells. The tumors removed from mice given cabozantinib of $10 \mathrm{mg} / \mathrm{kg}$ weighed $70 \%$ less than control on day 15, and the immunohistochemical reactivity of phosphorylated MET was reduced compared with control mice. Conclusion: Cabozantinib contributes to tumor reduction, and phosphorylated MET represents an attractive target of $C C C$.
\end{abstract}

Correspondence to: Hidemichi Watari, MD, Ph.D., Hokkaido University Graduate School of Medicine, North15, West7, Kita-ku, Sapporo, Hokkaido, 060-8638, Japan. Tel: +81 117065941, Fax: +81 117067711, e-mail: watarih@med.hokudai.ac.jp and Shinya Tanaka, Ph.D., Department of Cancer Pathology, Hokkaido University Graduate School of Medicine. North 15, West 7, Kitaku, Sapporo, Hokkaido, 060-8638, Japan. Tel: +81 117065052, Fax: +81 117065902, e-mail: tanaka@med.hokudai.ac.jp

Key Words: Ovarian cancer, clear cell carcinoma, MET, cabozantinib, RMG-I.
Ovarian cancer is the leading cause of death among malignancies of the female reproductive system, resulting in approximately 125,000 deaths annually (1). Clear cell carcinoma (CCC) of the ovary was first recognized by the World Health Organization as a distinct histologic subtype in 1973 (2). There are marked geographic differences in the prevalence of ovarian CCC, and the incidence of ovarian CCC in women living in United States is $4.8 \%$ in whites, $3.1 \%$ in blacks, and $11.1 \%$ in Asians (3). Improvements in the clinical outcomes of CCC patients have been poor because $\mathrm{CCC}$ is less sensitive to platinum-based first-line chemotherapy than other histological subtypes, including high-grade serous carcinoma or endometrioid carcinoma. The effect of standard combination chemotherapy with paclitaxel and carboplatin (TC) is not satisfactory for CCC (around 50\% for primary tumors), and other agents have failed to demonstrate superiority to TC (4-6). In addition, there is no effective chemotherapy for recurrent disease after treatment with platinum-based chemotherapy (7). The detailed molecular mechanisms that may contribute to drug resistance in CCC are still not fully understood, and new therapeutic strategies to overcome drug resistance need to be established.

The hepatocyte growth factor (HGF) signaling pathway may be a viable target for the development of directed therapeutic regimens for the treatment of ovarian cancer. HGF is the ligand of the HGF receptor, the MET protooncogene, receptor tyrosine kinase (MET), which has been reported to be expressed in approximately $60 \%$ of ovarian cancer cases (8). Overexpression of MET has been reported to be associated with a poor clinical outcome in ovarian cancer (8-11) and with chemoresistance of ovarian cancer cells $(12,13)$. Additionally, recent studies have reported that MET inhibitor could be used to overcome the resistance to cytotoxic agents in ovarian cancer $(13,14)$. These results 
prompted our hypothesis that MET inhibitor may be an active agent for a subset of CCC.

In this study, we searched for mechanisms involved in the effect of cabozantinib, a multi-receptor tyrosine kinase inhibitor for MET, ret proto-oncogene (RET), and kinase insert domain receptor (VEGFR2), that is already approved for progressive medullary thyroid cancer by the US Food and Drug Administration (15). We found that cabozantinib inhibited cell growth in vitro and tumor formation in nude mice bearing $\mathrm{CCC}$.

\section{Materials and Methods}

Comprehensive gene expression analysis. Total RNAs were extracted from tumor tissues derived from patients with CCC or high-grade serous carcinoma (HGSC) using the RNeasy Mini kit (Qiagen, Tokyo, Japan). Extracted total RNA was quantified using a Qubit 3.0 Fluorometer (Thermo Fisher Scientific, Waltham, MA, USA). Libraries for transcriptome were prepared using an Ion AmpliSeq ${ }^{\mathrm{TM}}$ Transcriptome Human Gene Expression Kit (Thermo Fisher Scientific). A total of $10 \mathrm{ng}$ of total RNAs were used to prepare the barcoded libraries. The prepared libraries were purified using AMPure XP (Beckman Coulter, Brea, CA, USA) and quantified using an Ion Library TaqMan ${ }^{\mathrm{TM}}$ Quantitation Kit (Thermo Fisher Scientific), then diluted to $50 \mathrm{pM}$ and pooled equally with eight samples per pool. Emulsion polymerase chain reaction was performed using the Ion $\mathrm{Chef}^{\mathrm{TM}}$ System. The templated libraries were then sequenced on Ion Proton ${ }^{\mathrm{TM}}$ system using the Ion P1 Hi-Q Chef Kit and Ion P1 Chip Kit v3 (Thermo Fisher Scientific).

Cell lines. The fully verified human ovarian CCC cell lines RMG-I (16), OVTOKO (17) and OVISE and the human ovarian mesonephroid adenocarcinoma cell line RMG-II (18) were purchased from JCRB Cell Bank (Osaka, Japan). The human ovarian CCC cell line ES-2 (19) was purchased from ATCC (Manassas, VA, USA). RMG-I cells were cultured in Ham's F12 with $10 \%$ fetal bovine serum (FBS), $2 \mathrm{mM}$ L-glutamine, and $100 \mathrm{U} / \mathrm{ml}$ penicillin and streptomycin. OVTOKO and OVISE cells were cultured in RPMI 1640 with $10 \%$ FBS, 2 mM L-glutamine and $100 \mathrm{U} / \mathrm{ml}$ penicillin and streptomycin. ES-2 cells were cultured in Dulbecco's modified Eagle's medium DMEM with 10\% FBS, 2 mM L-glutamine, and $100 \mathrm{U} / \mathrm{ml}$ penicillin and streptomycin.

Reagents. Cabozantinib (Selleck Chemicals, Houston, TX, USA) was dissolved in dimethyl sulfoxide (DMSO) and an equal volume of DMSO was used as control. Recombinant human hepatocyte growth factor (HGF) (Peprotech, Rocky Hill, NJ, USA) was dissolved in double distilled water DDW with $0.9 \% \mathrm{NaCl}$.

Analysis of MET signaling pathway in RMG-I cells. A total of $5 \times 10^{5}$ cells were inoculated onto 60-mm dishes. Six hours after attachment of the cells, the medium was changed to serum-free medium and cultured overnight at $37^{\circ} \mathrm{C}$. Cells were treated with $20 \mathrm{nM}$ of cabozantinib. After 1.5-h incubation, HGF $(50 \mathrm{ng} / \mathrm{ml})$ was added for $30 \mathrm{~min}$. At the end of treatment, the cells were collected and stored at $-80^{\circ} \mathrm{C}$ until western blot analyses.

Immunoblotting. Cells were lysed with lysis buffer (10mM Tris-HCl [pH 7.4], $150 \mathrm{mM} \mathrm{NaCl}, 1 \mathrm{mM}$ EDTA, $0.5 \% \mathrm{NP} 40,50 \mathrm{mM} \mathrm{NaF}$,
$1 \mathrm{mM}$ phenylmethylsulfonyl fluoride, $\left.1 \mathrm{mM} \mathrm{Na} \mathrm{VO}_{4}, \mathrm{PMSF}\right)$. Proteins were separated by SDS-polyacrylamide gel electrophoresis and transferred onto a polyvinylidene difluoride filter (Millipore, Billerica, MA, USA) by the standard method. Filters were incubated in TBS containing 2\% skim milk with rabbit polyclonal antibody against MET (Cell Signaling Technology, Danvers, MA, USA) with 1:1,000 dilution, RET (Cell Signaling Technology) with 1:1000 dilution, VEGFR2 (Cell Signaling Technology) with 1:250 dilution, and $\alpha$-tubulin (Santa Cruz Biotechnology, Dallas, TX, USA) with 1:2,000 dilution. For the detection of phospho-MET (pMET, Tyr1234/1235, Cell Signaling Technology), phospho-AKT (pAKT, Ser473, Cell Signaling Technology), and phospho-MAPK (pMAPK, Thr202/Tyr204, Cell Signaling Technology), filters were incubated in TBS containing 5\% bovine serum albumin and $1 \%$ tween-20 with rabbit polyclonal antibody against p-MET (Cell Signaling Technology) with 1:500 dilution, p-AKT (Cell Signaling Technology) with 1:500 dilution, and p-MAPK (Cell Signaling Technology) with 1:500 dilution. All filters were incubated overnight at $4^{\circ} \mathrm{C}$ and then with peroxidase-labeled secondary antibodies with 1:5,000 dilution for $1 \mathrm{~h}$ at room temperature. Proteins were visualized using a Novex ECL Chemiluminescent Substrate Reagent Kit (Invitrogen, Carlsbad, CA, USA) and quantified using a Lumino Image Analyzer (LAS1000; Fuji Film, Tokyo, Japan).

Measurement of drug sensitivity by the 3-(4, 5-dimethylthiazolyl-2)2, 5-diphenyltetrazolium bromide assay (MTT assay). The MTT assay was performed for drug sensitivity assays using Cell Proliferation Kit I (Roche, Mannheim, Germany) according to the manufacturer's instructions. Briefly, $5 \times 10^{3}$ cells were seeded onto 96-well plates in $100 \mu \mathrm{l}$ culture medium with reagents. An equal volume of DMSO was used as a control. The wavelength to measure the absorbance of the formazan product was $550 \mathrm{~nm}$, and the reference wavelength was $655 \mathrm{~nm}$.

Analysis of tumor-forming potential in vivo. All experiments were conducted in accordance with guidelines authorized by the Animal Research Committee Hokkaido University. Six-week-old BALB/c nude mice (Clea, Tokyo, Japan) were injected subcutaneously into their abdomen with $5 \times 10^{6}$ cells in $200 \mu$ l of matrigel (BD Biosciences, San Jose, CA, USA) and $50 \mu$ of normal culture medium. The tumors reached $100 \mathrm{~mm}^{3}$ after 4 days. Then, the mice were randomly assigned to one of four treatment groups, receiving any of three concentrations ( $3 \mathrm{mg} / \mathrm{kg}, 10 \mathrm{mg} / \mathrm{kg}, 30 \mathrm{mg} / \mathrm{kg}$ ) of cabozantinib. An equal volume of DMSO was used as control. Oral cabozantinib administration was started once a day for 14 days. The tumor size was measured every three days. All mice were killed on day 15, and the tumor weight was measured and photos taken. Xenograft tumors were fixed in formalin and embedded in paraffin. They were used for immunohistochemistry later.

Immunohistochemistry. Tissue sections were deparaffinized in xylene and rehydrated through a series of graded ethanol washes. Heat-induced antigen retrieval was carried-out in high-pH antigen retrieval buffer (Dako, Glostrup, Denmark). Endogenous peroxidase was blocked by incubation in $3 \% \mathrm{H}_{2} \mathrm{O}_{2}$ for $5 \mathrm{~min}$. The primary antibodies against MET and p-MET (SP44 and SP58, respectively; Spring Bioscience, Pleasanton, CA, USA) were applied for $30 \mathrm{~min}$. These sections were visualized by the HRP-labeled polymer method (EnVision FLEX system in human tissues and EnVision+ system for 


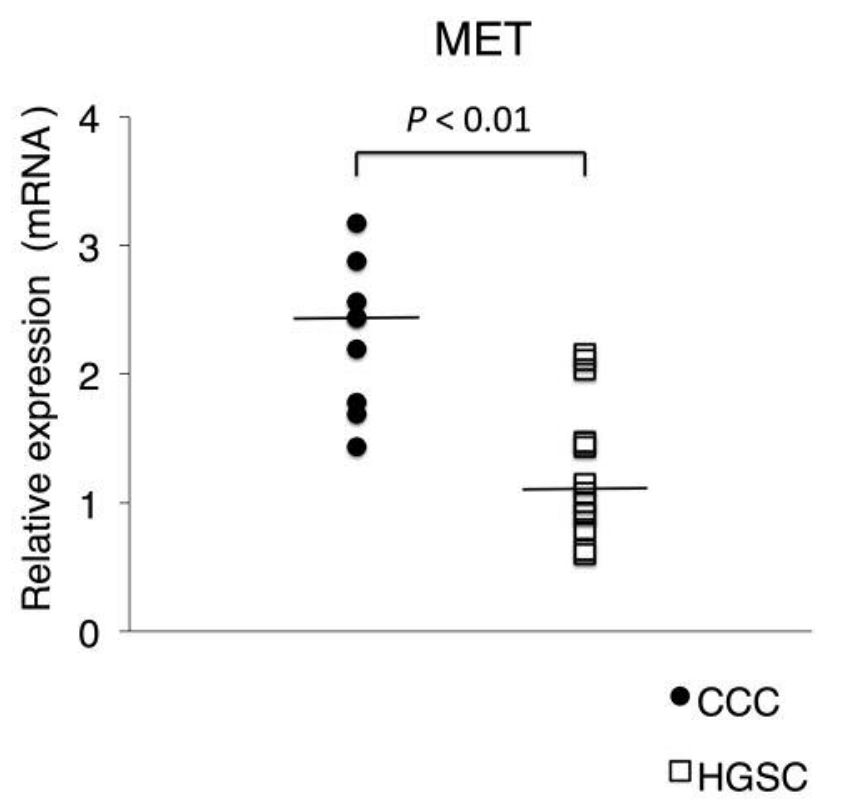

Figure 1. MET mRNA expression in CCC and HGSC. Transcriptome sequencing of MET mRNA in 9 CCC tumors and 14 HGSC tumors. The Mann-Whitney U-test was used for statistical analysis. The horizontal lines demonstrate the median.

Rabbit in mouse xenograft tissues, respectively; Dako). Immunostained sections were counterstained with hematoxylin, dehydrated in ethanol, and cleared in xylene.

Statistical analyses. For in vitro and in vivo studies, continuous variables were compared using nonparametric Mann-Whitney $U$-test or Student's $t$-test if normally distributed. Data are presented as the medians or means \pm standard error (SE). For animal experiments, the tumor weight was presented as the means \pm SE. All statistical tests were two-sided, and $p$-values less than 0.05 were considered significant. Only two-tailed values were reported.

\section{Results}

mRNA expression of MET in clinical tumor tissue samples. We first examined the mRNA expression of MET in frozen clinical tissue specimens from 9 of CCC and 14 of HGSC by transcriptome sequencing. MET mRNA expression level was upregulated in CCC than HGSC (2.2-fold), suggesting that CCC might be more strongly dependent on MET signaling pathway for tumor progression than HGSC, and MET could be a good therapeutic target for CCC (Figure 1).

Analysis of the MET signaling pathway with or without cabozantinib treatment in RMG-I cells (CCC cell line). Given the MET activation found in CCC tumor specimens, we evaluated the basal level of expression of MET and p-

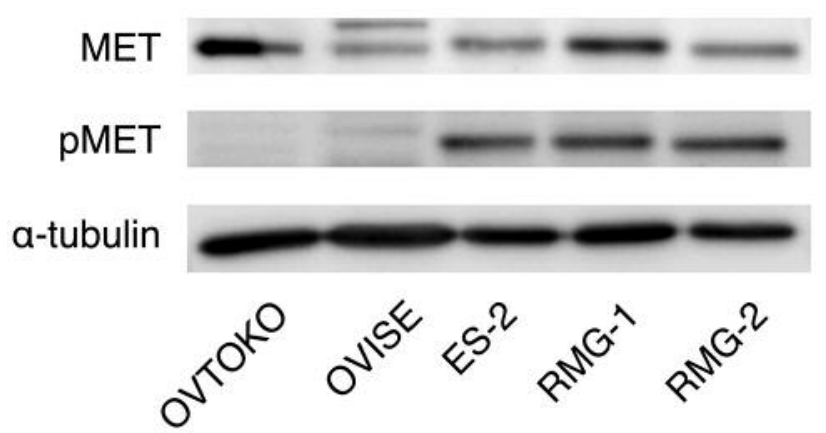

Figure 2. The basal level of expression of MET and p-MET in CCC cell lines. Immunoblot of MET, phosphorylated-MET (pMET) and $\alpha$-tubulin in OVTOKO, OVISE, ES-2, RMG-1 and RMG-2 cells.

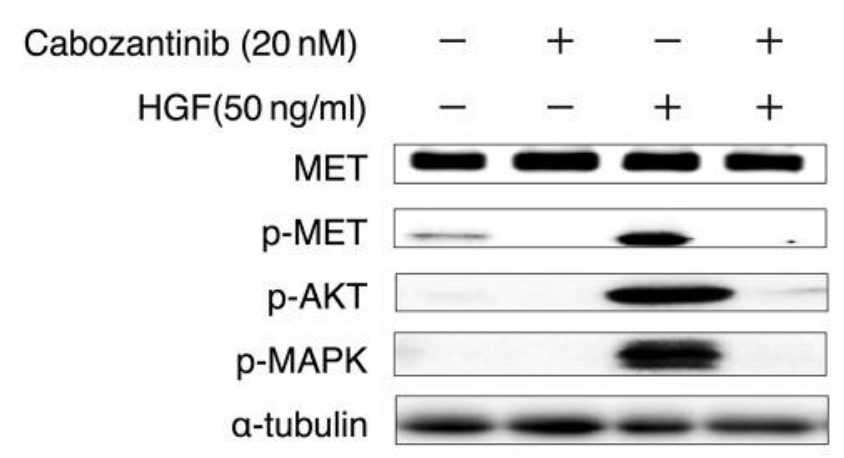

Figure 3. Effect of cabozantinib on the MET signaling pathway in RMG-I cells. Immunoblot of MET, phosphorylated-MET (pMET), phosphorylatedAKT (pAKT), phosphorylated-MAPK (pMAPK) and $\alpha$-tubulin in RMG-I cells treated with or without cabozantinib.

MET in a CCC cell lines. Among five fully-verified CCC cell lines, both MET and p-MET levels were highest in RMG-I cells by a western blot analysis (Figure 2). The expression of both RET and VEGFR2 were low in RMG-I cells (data not shown). The MET expression in RMG-I cells was not changed with the treatment of HGF $(50 \mathrm{ng} / \mathrm{ml})$, a ligand for MET, while the expression of p-MET was induced. HGF also induced the phosphorylation of AKT and MAPK, which are the downstream targets of MET in RMGI cells (Figure 3). These findings suggested that RMG-I was most suitable for the present study.

We next examined the expression of MET and p-MET under the treatment of cabozanitinib (20 nM) in RMG-I cells. Cabozanitnib did not affect the expression of MET but significantly suppressed the expression of p-MET without HGF treatment. The expression of p-MET, p-AKT, and 


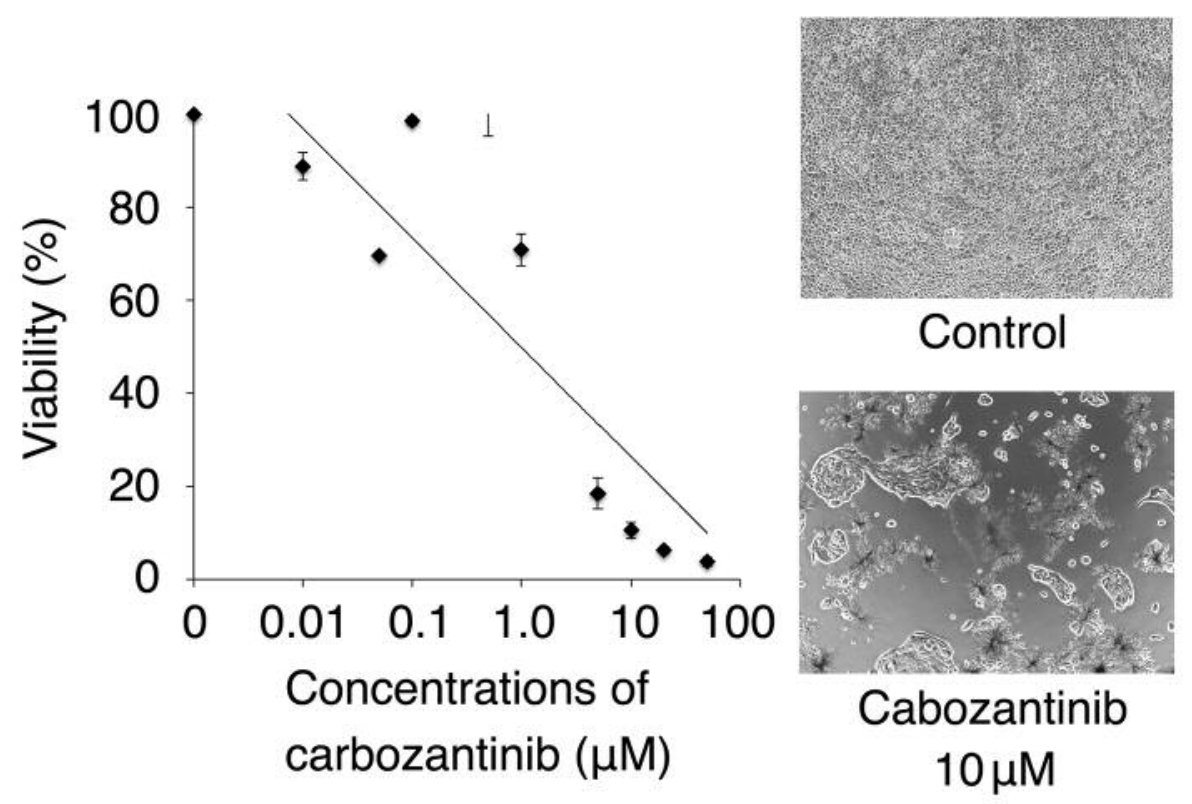

Figure 4. Anti-proliferative effect of cabozantinib on RMG-I cells in vitro. Direct effects of cabozantinib on RMG-I viability. Left: Viability at each concentration. Data are presented as the means \pm SE. Right: Representative images of control and $10 \mu M$ of cabozantinib.

p-MAPK induced by HGF (50 $\mathrm{ng} / \mathrm{ml})$ was subsequently inhibited by the treatment of cabozantinib (Figure 3).

Cabozanitinib inhibited viability of RMG-I cells in vitro. We next examined the inhibitory effect of cabozantinib on the viability of RMG-I cells in vitro. We investigated the antiproliferative effect of cabozantinib by an MTT assay. Cabozantinib showed anti-proliferative effect on RMG-I cells, and we found that the $\mathrm{IC}_{50}$ of cabozantinib was $1.0 \mu \mathrm{M}$ for RMG-I cells (Figure 4).

Cabozanitinib inhibited tumor growth of RMG-I cells in vivo. To further examine the in vivo growth inhibitory effect of cabozantinib, we employed a mouse xenograft model, in which athymic mice were inoculated subcutaneously with RMG-I cells. Drug treatment was well-tolerated except in 1 mouse treated with $30 \mathrm{mg} / \mathrm{kg}$ of cabozantinib that died of aspiration. $3 \mathrm{mg} / \mathrm{kg}, 10 \mathrm{mg} / \mathrm{kg}$ and $30 \mathrm{mg} / \mathrm{kg}$ of cabozantinib significantly inhibited tumor formation after day 15 (Student's $t$-test $p<0.01$, respectively) compared to vehicle-treated tumors (Figure $5 \mathrm{~A}$ and $\mathrm{B}$ ). The tumors removed from mice given cabozantinib of both $10 \mathrm{mg} / \mathrm{kg}(177 \mathrm{mg})$ and $30 \mathrm{mg} / \mathrm{kg}(177 \mathrm{mg})$ weighed $72 \%$ less than control (623 mg) on day 15.

Immunohistochemical expression of MET and p-MET in the mouse xenograft tissues of RMG-I cells with or without cabozantinib treatment. We examined the expression of MET and p-MET in the tissue sections of mouse xenografts of RMG-I cells. To investigate the cancer cell-specific expression of MET and phospho-MET, we evaluated the expression of MET and phospho-MET microscopically. Immunohistochemistry showed that the MET expression was not altered by cabozantinib treatment. In contrast, the expression of p-MET was suppressed in tumors treated with cabozaninib (10 mg/kg and $30 \mathrm{mg} / \mathrm{kg}$ ) compared to those without cabozantinib treatment (Figure 6), suggesting that the anti-tumor activity of cabozantinib was mainly dependent on the inhibition of phosphorylation of MET.

\section{Discussion}

Previous reports have suggested several molecular mechanisms underlying the resistance of $\mathrm{CCC}$ to conventional chemotherapy that included the HNF-1 $\beta$ pathway, PI3K/AKT/mTOR pathway, and MET pathway (7). For the PI3K/AKT/mTOR pathway, the clinical efficacy of the mTOR inhibitor temsirolimus has been evaluated for advanced-stage CCC in a phase II trial (GOG268) in both the US and Japan (45 patients each). However, temsirolimus failed to show a significant survival benefit for advancedstage CCC in combination with TC and in consolidation as first-line chemotherapy (20). Another mTOR inhibitor, everolimus, is expected to be less effective than cabozantinib because a recent phase III trial demonstrated that 
A

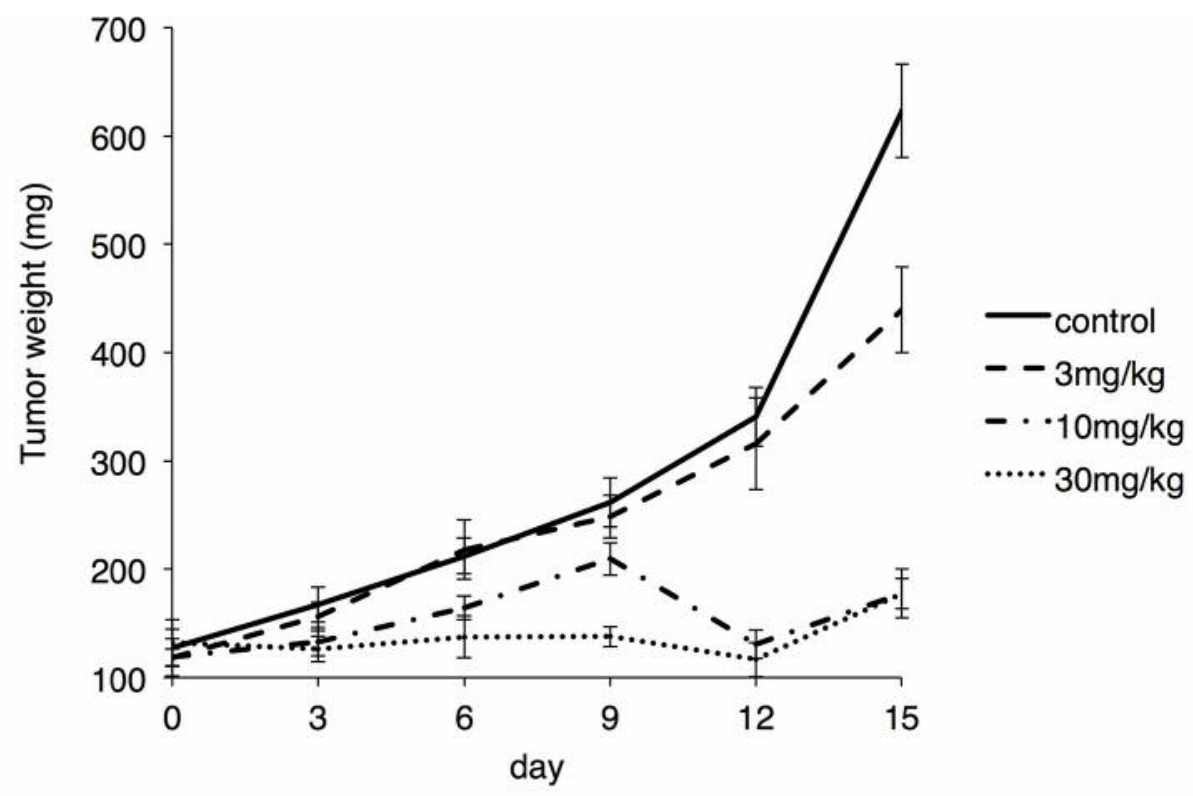

B
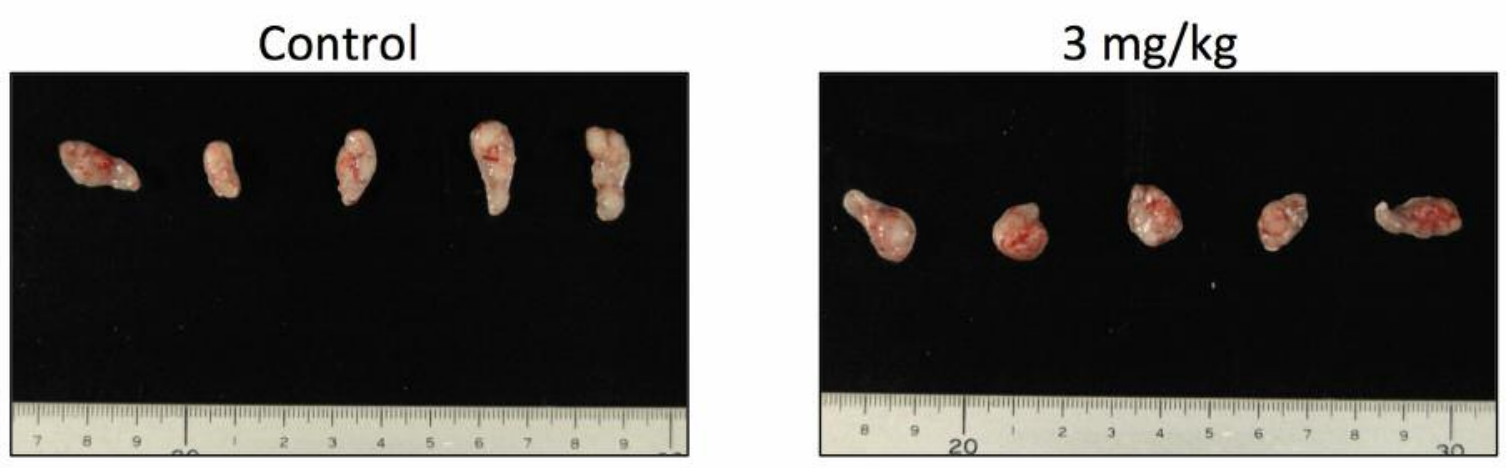

$10 \mathrm{mg} / \mathrm{kg}$

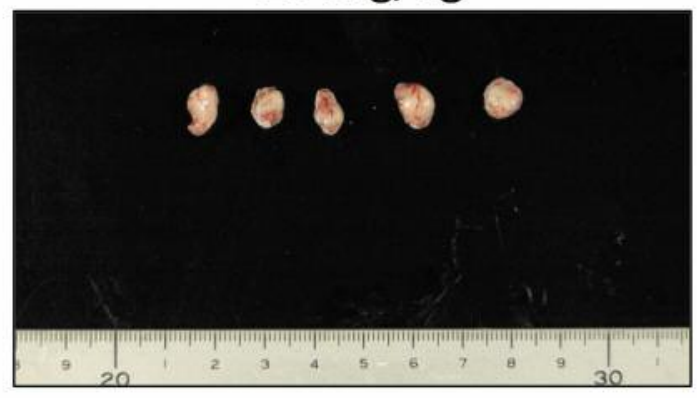

$30 \mathrm{mg} / \mathrm{kg}$

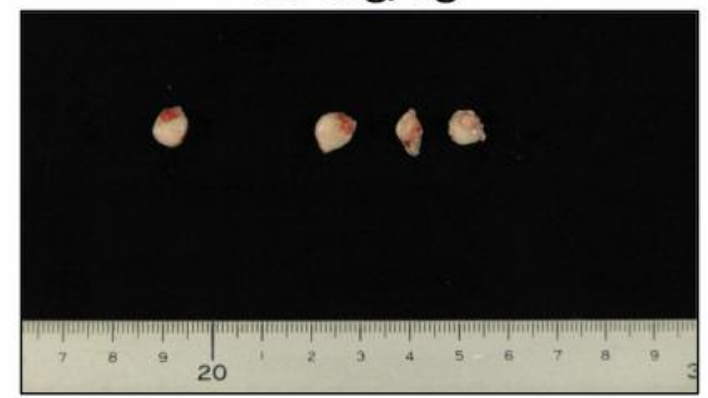

Figure 5. Sensitization of RMG-I tumors to cabozantinib in vivo. (A) Tumor weights of tumor nodules in the control and cabozantinib groups of mice. Data are presented as the means \pm SE. (B) Representative images of the subcutaneous tumors in the control and cabozantinib groups of mice.

cabozantinib significantly improved the survival of patients with advanced-stage renal CCC compared to everolimus (21).

Several reports have shown that the amplification and/or overexpression of MET, which is a target of cabozantinib
(22), was quite common and more frequently observed in CCC of the ovary than in non-CCC based on the findings from immunohistochemistry and/or in situ hybridization. In addition, this overexpression is associated with a poor 


\section{$H \& E$}

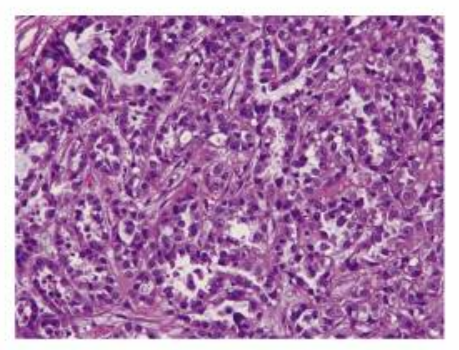

Control

\section{Cabozantinib $10 \mathrm{mg} / \mathrm{kg}$}
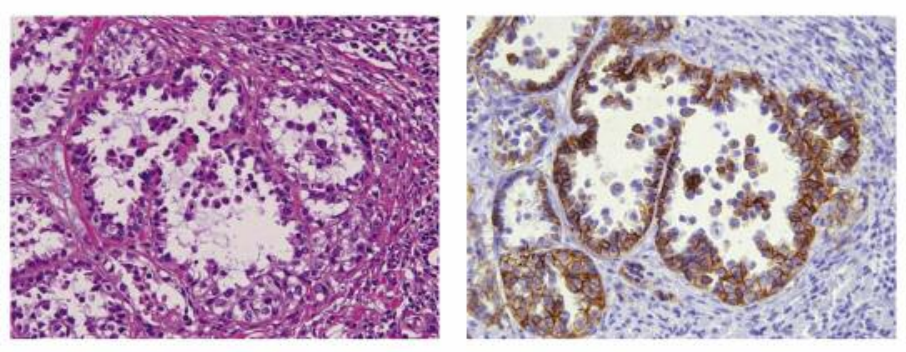

MET
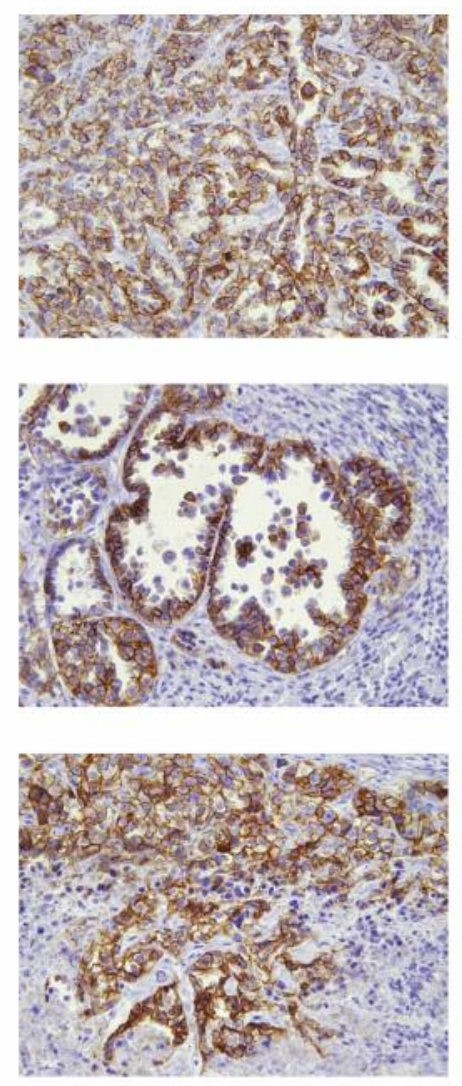

p-MET
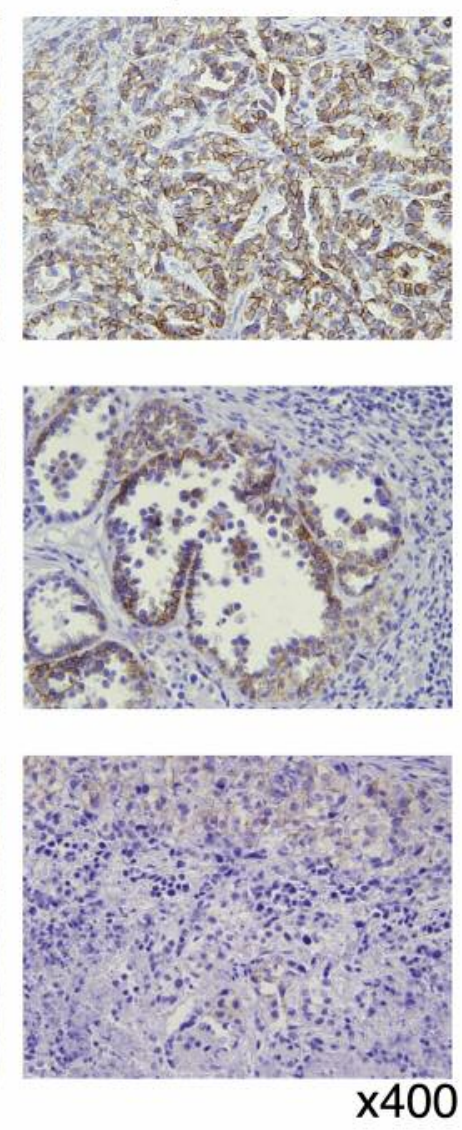

Figure 6. Cabozantinib therapy suppresses the phosphorylated-MET expression in CCC in vivo. An immunohistochemical analysis of MET and pMET expression in sections of control and cabozantinib-treated RMG-I tumors.

prognosis of patients with CCC $(11,23)$. Cabozantinib was tested in a phase II trial for 70 cases of recurrent ovarian cancer (24). In that trial, the response rate of cabozantinib for refractory/resistant disease (recurrence within 6 months after the last chemotherapy session) and sensitive disease (recurrence over 6 months after the last chemotherapy session) was $20.6 \%$ (7/34) and $27.8 \%$ (10/36), respectively. The disease control rate (complete response + partial response + stable disease) for refractory/resistant disease and sensitive disease was $38.2 \%(13 / 34)$ and $66.7 \%$ (24/36), respectively. Thus, cabozantinib seems a promising agent for recurrent ovarian cancer. However, its efficacy for $\mathrm{CCC}$ has not been fully evaluated, as only 3 patients with recurrent CCC $(4.3 \%$, $3 / 70$ ) were enrolled in the previous phase II study. We, therefore, conducted the current experiments to investigate the anti-tumor effect of cabozantinib for CCC of the ovary. In our in vivo study, tumor reduction was the same for both $10 \mathrm{mg} / \mathrm{kg}$ and $30 \mathrm{mg} / \mathrm{kg}$, suggesting the existence of dose limitation of cabozantinib in terms of clinical response to
CCC. In the previous human clinical trials, the dose range was from 60 to $100 \mathrm{mg}$ daily $(21,25-27)$. Although the concentration was high in our in vivo study, the results of the current study suggest that the anti-MET activity of cabozantinib should be prospectively tested for CCC patients with advanced-stage or recurrent disease with a poor prognosis. Indeed, the NRG oncology group has been conducting phase II trial testing of cabozantinib for advancedstage ovarian CCC patients with recurrent disease (NRG-GY001) (28). For further basic investigations of the effect of cabozantinib, the establishment of a human ovarian CCC cell line expressing RET and VEGFR2 will be needed.

\section{Conclusion}

Our findings suggest that cabozantinib might be an active agent for a CCC cell line through in vitro and in vivo studies. Ongoing phase II trials may reveal that cabozantinib is effective for advanced-stage recurrent $\mathrm{CCC}$ patients and will 
be approved for recurrent advanced-stage ovarian CCC in patients with a poor prognosis to improve their survival. Cabozantinib should be prospectively tested for ovarian CCC patients with a poor prognosis.

\section{Conflicts of Interest}

The Authors report no conflicts of interest in this work.

\section{References}

1 Boyle P and Levin B: World cancer report 2008: World Health Organization, 2008.

2 Serov SF, Scully RE and Sobin LH: Histological Typing of Ovarian Tumours: Geneva: World Health Organization, 1973.

3 Anglesio MS, Carey MS, Kobel M, Mackay H and Huntsman DG: Clear cell carcinoma of the ovary: a report from the first Ovarian Clear Cell Symposium, June 24th, 2010. Gynecol Oncol 121: 407-415, 2011.

4 Utsunomiya H, Akahira J, Tanno S, Moriya T, Toyoshima M, Niikura H, Ito K, Morimura Y, Watanabe Y and Yaegashi N: Paclitaxel-platinum combination chemotherapy for advanced or recurrent ovarian clear cell adenocarcinoma: a multicenter trial. Int J Gynecol Cancer 16: 52-56, 2006.

5 Ho CM, Huang YJ, Chen TC, Huang SH, Liu FS, Chang Chien CC, Yu MH, Mao TL, Wang TY and Hsieh CY: Pure-type clear cell carcinoma of the ovary as a distinct histological type and improved survival in patients treated with paclitaxel-platinumbased chemotherapy in pure-type advanced disease. Gynecol Oncol 94: 197-203, 2004.

6 Sugiyama T, Okamoto A, Enomoto T, Hamano T, Aotani E, Terao Y, Suzuki N, Mikami M, Yaegashi N, Kato K, Yoshikawa H, Yokoyama Y, Tanabe H, Nishino K, Nomura H, Kim JW, Kim BG, Pignata S, Alexandre J, Green J, Isonishi S, Terauchi F, Fujiwara K and Aoki D: Randomized phase III trial of irinotecan plus cisplatin compared with paclitaxel plus carboplatin as firstline chemotherapy for ovarian clear cell carcinoma: JGOG3017/GCIG Trial. J Clin Oncol 34: 2881-2887, 2016.

7 Mabuchi S, Sugiyama T and Kimura T: Clear cell carcinoma of the ovary: molecular insights and future therapeutic perspectives. J Gynecol Oncol 27: e31, 2016.

8 Ayhan A, Ertunc D, Tok EC and Ayhan A: Expression of the cMet in advanced epithelial ovarian cancer and its prognostic significance. Int J Gynecol Cancer 15: 618-623, 2005.

9 Di Renzo MF, Narsimhan RP, Olivero M, Bretti S, Giordano S, Medico E, Gaglia P, Zara P and Comoglio PM: Expression of the Met/HGF receptor in normal and neoplastic human tissues. Oncogene 6: 1997-2003, 1991.

10 Sawada K, Radjabi AR, Shinomiya N, Kistner E, Kenny H, Becker AR, Turkyilmaz MA, Salgia R, Yamada SD, Vande Woude GF, Tretiakova MS and Lengyel E: c-Met overexpression is a prognostic factor in ovarian cancer and an effective target for inhibition of peritoneal dissemination and invasion. Cancer Res 67: 1670-1679, 2007.

11 Yamamoto S, Tsuda H, Miyai K, Takano M, Tamai S and Matsubara O: Gene amplification and protein overexpression of MET are common events in ovarian clear-cell adenocarcinoma: their roles in tumor progression and prognostication of the patient. Mod Pathol 24: 1146-1155, 2011.
12 Tang MK, Zhou HY, Yam JW and Wong AS: c-Met overexpression contributes to the acquired apoptotic resistance of nonadherent ovarian cancer cells through a cross talk mediated by phosphatidylinositol 3-kinase and extracellular signal-regulated kinase 1/2. Neoplasia 12: 128-138, 2010.

13 Mitamura T, Watari H, Wang L, Kanno H, Hassan MK, Miyazaki M, Katoh Y, Kimura T, Tanino M, Nishihara H, Tanaka S and Sakuragi N: Downregulation of miRNA-31 induces taxane resistance in ovarian cancer cells through increase of receptor tyrosine kinase MET. Oncogenesis 2: e40, 2013.

14 Marchion DC, Bicaku E, Xiong Y, Bou Zgheib N, Al Sawah E, Stickles XB, Judson PL, Lopez AS, Cubitt CL, GonzalezBosquet J, Wenham RM, Apte SM, Berglund A and Lancaster JM: A novel c-Met inhibitor, MK8033, synergizes with carboplatin plus paclitaxel to inhibit ovarian cancer cell growth. Oncol Rep 29: 2011-2018, 2013.

15 Elisei R, Schlumberger MJ, Muller SP, Schoffski P, Brose MS, Shah MH, Licitra L, Jarzab B, Medvedev V, Kreissl MC, Niederle B, Cohen EE, Wirth LJ, Ali H, Hessel C, Yaron Y, Ball D, Nelkin B and Sherman SI: Cabozantinib in progressive medullary thyroid cancer. J Clin Oncol 31: 36393646, 2013.

16 Nozawa S, Tsukazaki K, Sakayori M, Jeng CH and Iizuka R: Establishment of a human ovarian clear cell carcinoma cell line (RMG-I) and its single cell cloning - with special reference to the stem cell of the tumor. Hum Cell 1: 426-435, 1988.

17 Gorai I, Nakazawa T, Miyagi E, Hirahara F, Nagashima Y and Minaguchi $\mathrm{H}$ : Establishment and characterization of two human ovarian clear cell adenocarcinoma lines from metastatic lesions with different properties. Gynecol Oncol 57: 33-46, 1995.

18 Nozawa S, Yajima M, Sasaki H, Tsukazaki K, Aoki D, Sakayori M, Udagawa Y, Kobayashi T, Sato I, Furusako S et al: A new CA125-like antigen (CA602) recognized by two monoclonal antibodies against a newly established ovarian clear cell carcinoma cell line (RMG-II). Jpn J Cancer Res 82: 854-861, 1991.

19 Lau DH, Lewis AD, Ehsan MN and Sikic BI: Multifactorial mechanisms associated with broad cross-resistance of ovarian carcinoma cells selected by cyanomorpholino doxorubicin. Cancer Res 51: 5181-5187, 1991.

20 Farley JH, Brady WE, Fujiwara K, Nomura H, Yunokawa M, Tokunaga H, Saitou $M$ and Gershenson DM: A phase II evaluation of temsirolimus in combination with carboplatin and paclitaxel followed by temsirolimus consolidation as first-line therapy in the treatment of stage iii-iv clear cell carcinoma of the ovary. 2016 ASCO Annual Meeting. J Clin Oncol 34: abstr 5531,2016

21 Choueiri TK, Escudier B, Powles T, Tannir NM, Mainwaring PN, Rini BI, Hammers HJ, Donskov F, Roth BJ, Peltola K, Lee JL, Heng DY, Schmidinger M, Agarwal N, Sternberg CN, McDermott DF, Aftab DT, Hessel C, Scheffold C, Schwab G, Hutson TE, Pal S and Motzer RJ: Cabozantinib versus everolimus in advanced renal cell carcinoma (METEOR): final results from a randomised, open-label, phase 3 trial. Lancet Oncol 17: 917-927, 2016.

22 Weidle UH, Birzele F, Kollmorgen G and Rueger R: Mechanisms and targets involved in dissemination of ovarian cancer. Cancer Genomics Proteomics 13: 407-423, 2016. 
23 Yamashita Y, Akatsuka S, Shinjo K, Yatabe Y, Kobayashi H, Seko H, Kajiyama H, Kikkawa F, Takahashi T and Toyokuni S: Met is the most frequently amplified gene in endometriosisassociated ovarian clear cell adenocarcinoma and correlates with worsened prognosis. PLoS One 8: e57724, 2013.

24 Buckanovich RJ, Berger R, Sella A, Sikic BI, Shen X, Ramies DA, Smith DC and Vergote IB: Activity of cabozantinib (XL184) in advanced ovarian cancer patients (pts): Results from a phase II randomized discontinuation trial (RDT). 2011 ASCO Annual Meeting. J Clin Oncol 29: abstr 5008, 2011.

25 Leibowitz-Amit R, Pintilie M, Khoja L, Azad AA, Berger R, Laird AD, Aftab DT, Chi KN and Joshua AM: Changes in plasma biomarkers following treatment with cabozantinib in metastatic castration-resistant prostate cancer: a post hoc analysis of an extension cohort of a phase II trial. J Transl Med 14: 12, 2016.

26 Zuo RC, Apolo AB, DiGiovanna JJ, Parnes HL, Keen CM, Nanda S, Dahut WL and Cowen EW: Cutaneous adverse effects associated with the tyrosine-kinase inhibitor cabozantinib. JAMA Dermatol 151: 170-177, 2015.
27 Smith DC, Smith MR, Sweeney C, Elfiky AA, Logothetis C, Corn PG, Vogelzang NJ, Small EJ, Harzstark AL, Gordon MS, Vaishampayan UN, Haas NB, Spira AI, Lara PN, Jr., Lin CC, Srinivas S, Sella A, Schoffski P, Scheffold C, Weitzman AL and Hussain M: Cabozantinib in patients with advanced prostate cancer: results of a phase II randomized discontinuation trial. J Clin Oncol 31: 412-419, 2013.

28 NRG-GY001: A phase II trial of cabozantinib (XL-184) (NSC \#761968) in women with recurrent, clear cell carcinoma of the ovary, fallopian tube, or peritoneum. National Cancer Institute (NCI), 2017.
Received June 23, 2017

Revised July 18, 2017

Accepted July 19, 2017 